\title{
The SASSCAL contribution to climate observation, climate data management and data rescue in Southern Africa
}

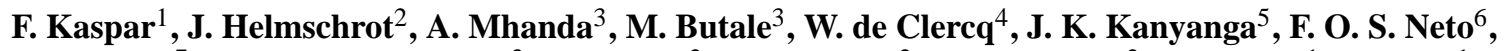 \\ S. Kruger ${ }^{7}$, M. Castro Matsheka ${ }^{3}$, G. Muche ${ }^{2}$, T. Hillmann ${ }^{2}$, K. Josenhans ${ }^{2}$, R. Posada ${ }^{1}$, J. Riede ${ }^{1}$, \\ M. Seely ${ }^{8}$, C. Ribeiro ${ }^{9}$, P. Kenabatho ${ }^{10}$, R. Vogt $^{11}$, and N. Jürgens ${ }^{2}$ \\ ${ }^{1}$ Deutscher Wetterdienst, National Climate Monitoring, Frankfurter Str. 135, 63067 Offenbach, Germany \\ ${ }^{2}$ University of Hamburg; Biodiversity, Evolution and Ecology of Plants; Hamburg, Germany \\ ${ }^{3}$ Department of Meteorological Services (DMS), Gaborone, Botswana \\ ${ }^{4}$ Stellenbosch University, Stellenbosch, South Africa \\ ${ }^{5}$ Zambia Meteorological Department (ZMD), Lusaka, Zambia \\ ${ }^{6}$ Instituto Nacional de Meteorologia e Geofisica (INAMET), Luanda, Angola \\ ${ }^{7}$ National Botanical Research Institute, Windhoek, Namibia \\ ${ }^{8}$ Gobabeb Research and Training Centre, Walvis Bay, Namibia \\ ${ }^{9}$ Instituto Superior Politécnico Tundavala, Lubango, Angola \\ ${ }^{10}$ University of Botswana, Gaborone, Botswana \\ ${ }^{11}$ University of Basel, Basel, Switzerland \\ Correspondence to: F. Kaspar (frank.kaspar@dwd.de)
}

Received: 25 January 2015 - Revised: 22 June 2015 - Accepted: 26 June 2015 - Published: 24 July 2015

\begin{abstract}
A major task of the newly established "Southern African Science Service Centre for Climate Change and Adaptive Land Management" (SASSCAL; www.sasscal.org) and its partners is to provide science-based environmental information and knowledge which includes the provision of consistent and reliable climate data for Southern Africa. Hence, SASSCAL, in close cooperation with the national weather authorities of Angola, Botswana, Germany and Zambia as well as partner institutions in Namibia and South Africa, supports the extension of the regional meteorological observation network and the improvement of the climate archives at national level. With the ongoing rehabilitation of existing weather stations and the new installation of fully automated weather stations (AWS), altogether 105 AWS currently provide a set of climate variables at 15, 30 and $60 \mathrm{~min}$ intervals respectively. These records are made available through the SASSCAL WeatherNet, an online platform providing near-real time data as well as various statistics and graphics, all in open access. This effort is complemented by the harmonization and improvement of climate data management concepts at the national weather authorities, capacity building activities and an extension of the data bases with historical climate data which are still available from different sources. These activities are performed through cooperation between regional and German institutions and will provide important information for climate service related activities.
\end{abstract}




\section{Introduction}

Africa is considered being the most vulnerable continent regarding climate variability and change (e.g. as stated by the Working Group 2 of the IPCC 5th Assessment Report; IPCC, 2014). The preparation of an adequate response to the expected changes leads to an increasing demand for climate information and associated service capacities. Such activities are a basis for impact assessment research, climate adaptation measures and climate services at global, continental and regional scales. Addressing these issues, the World Meteorological Organization (WMO) established the Global Framework for Climate Services (GFCS) in order to provide a worldwide mechanism for coordinated actions to enhance the quality, quantity and application of climate services. In that context it was noted that the majority of developing countries still lack the resources and expertise they need to provide effective climate services to their citizens (WMO, 2014a). Observations of various parameters are required as a basis for such services. They have to be of adequate quality and quantity and should be measured at high temporal and spatial resolutions (WMO, 2014b).

Global infrastructures for exchange of meteorological observations have been in operation for decades, but their status and performance depend on the region. Figure 1 illustrates the status of the exchange of the so-called "CLIMAT"reports. The figure reveals that especially for large parts of Africa only a small amount of the expected data is available. It further indicates that existing national networks in sub-Saharan Africa are either not sufficient or service capacities are strongly limited. Improvements of the existing observational networks are urgently needed in order to achieve a better regional and global coverage with high quality and reliable climatological data. Thus, many national and international efforts are being undertaken to improve national station networks (e.g. within the GCOS (Global Climate Observing System) Cooperation Mechanism) and to implement advanced technologies for information management and exchange, often aligned with capacity development (e.g. within the WMO Voluntary Cooperation Programme).

In addition to the required improvements in the data availability of current weather conditions, the availability of longterm climate records is also limited for several Southern African countries. Partly, observations have been performed over long periods and have been documented manually on hard copies and stored in archives, but are not available in digital format, and are therefore not easily accessible for climate applications. Figure 2 shows an example of time series from Angola. The figure illustrates that observations for historical periods are available in international archives, but may vary in their availability over time. Historic documents with weather observations are partly available in the archives of the national meteorological services, but older data might also be available elsewhere, e.g. in archives of European meteorological services. In the archives of Germany's national

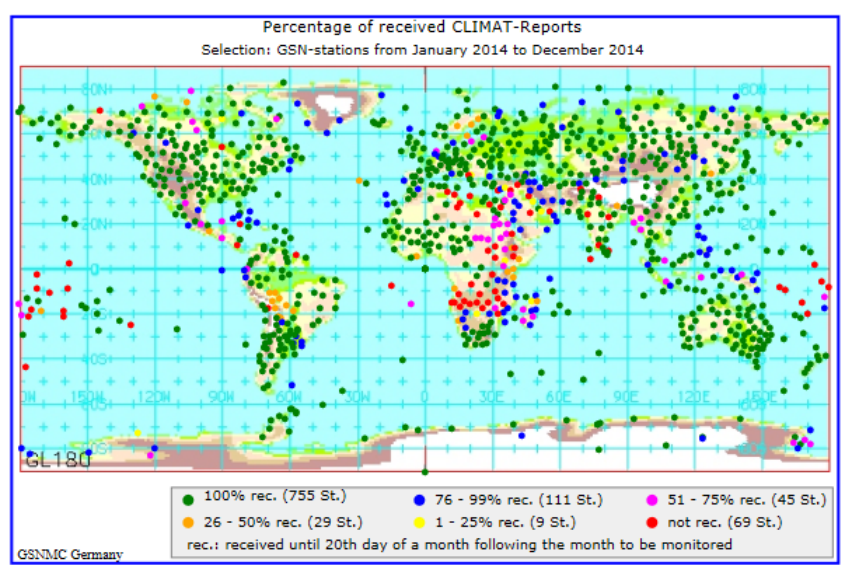

Figure 1. Percentage of received monthly CLIMAT-reports from the "GCOS Surface Network stations (GSN)" for the period January 2014 to December 2014. CLIMAT-reports are monthly summaries for special observing stations on the land surface that are collected and disseminated via the Global Telecommunication System (GTS) of the WMO within the so-called GCOS Surface Network ("Global Climate Observing System - Surface Network": GSN). The performance of this data exchange is monitored by two 'GSN Monitoring Centers' ("GSNMC"), one of them operated by Deutscher Wetterdienst (DWD). Colors indicate the percentage of reports that were received by the GSN Monitoring Center of DWD until the 20th day of a month following the month to be observed (Source: www.gsnmc.dwd.de).

meteorological service (Deutscher Wetterdienst, DWD), historical documents with weather observations from overseas stations and marine weather observations from ships (sailing ships, buoys steamers and light vessels) are available from several years at the beginning of the 20th century (Kaspar et al., 2015).

In summary, several activities are needed to improve the availability of climate data for Southern Africa: an enhancement of the observation network, an improvement of data management concepts and data rescue activities. With this paper, we give an overview on SASSCAL contributions addressing this deficit and specifically refer to the technical implementation which is conducted as a joint effort of various key institutions from Southern Africa and Germany.

\section{The Southern African Science Service Centre for Climate Change and Adaptive Land Management}

The implementation of such activities requires financial support and the cooperation of relevant institutions, especially the involvement of the national meteorological services. As a regional initiative, SASSCAL is an example of an activity that provides support for cooperation, technical infrastructure enhancement and implementation, and the improvement of capacities of regional institutions and service providers. 


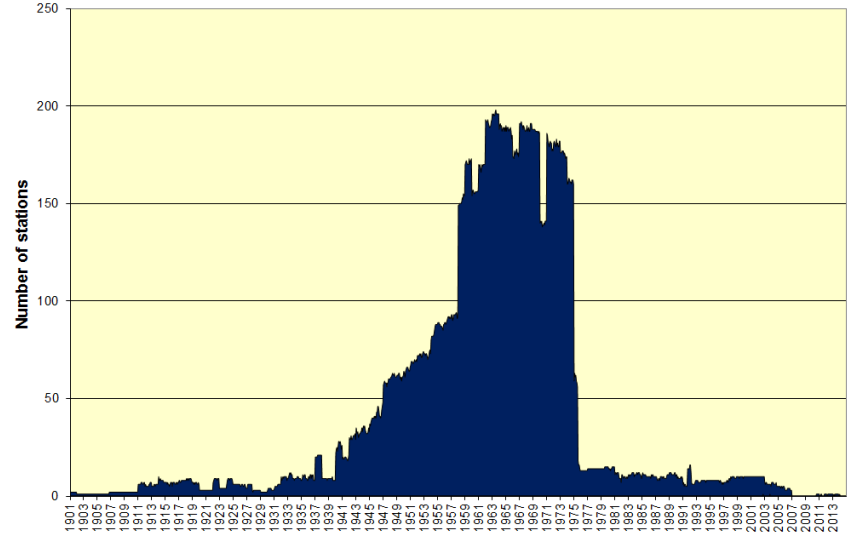

Figure 2. Number of stations with monthly precipitation data from Angola available in the database of Global Precipitation Climatology Center (GPCC) from 1901 to 2014 (status: 2014). Those stations were used for the GPCC Full Data Product (Schneider et al., 2014). GPCC is hosted at DWD.

The overarching aim of SASSCAL is to improve the capacities to provide sound science-based solutions for current problems and future risks in the region, in particular regarding climate change and the associated demands concerning land management practices of local players. As many of the global change challenges go beyond national boundaries, SASSCAL has a regional scope. It is a joint initiative of Angola, Botswana, Namibia, South Africa, Zambia and Germany. The main objectives therefore are:

1. trans-disciplinary, problem-oriented research in the area of adaptation to climate change and sustainable land management in order to improve the livelihoods of people in the region,

2. services and advice for policy, decision makers and stakeholders and

3. capacity development.

A full description of aims, objectives and intended services is given at www.sasscal.org.

One specific intention is to make data and information available for further scientific uses as well as to generate, compile, analyze and process relevant data on various topics, such as climate, the water cycle, soil fertility, forest resources, agriculture, biodiversity and socio-economy, in cooperation with national and, if required, with international authorities.

In the following sections, we only focus on SASSCAL activities related to climatological ground-based observations.

\section{SASSCAL WeatherNet}

The SASSCAL WeatherNet (www.sasscalweathernet.org) has been established in order to support climate data avail- ability for the SASSCAL region and is continuously under development. It comprises two major components, the regional station network itself and the online platform linking various tools for data repository, management and online visualization.

The station network covering all SASSCAL countries unifies

1. existing automatic weather stations of the previous initiative BIOTA AFRICA (www.biota-africa.org) and contributions of the Namibian Ministry of Agriculture, Water and Forestry,

2. new automatic weather stations (AWS) installed as a joint effort of SASSCAL, the national authorities and a Namibian NGO to improve national networks,

3. weather stations installed by individual SASSCAL research projects (experimental networks) and

4. rehabilitated stations from former monitoring efforts.

Complementing the former BIOTA network consisting of 40 automatic weather stations and in support of national efforts of Angola, Botswana and Zambia to improve their national weather monitoring systems, SASSCAL installed 10 fully automatic weather stations in each of the three countries in 2013/2014. For detailed studies on climatological phenomena, nine AWSs were installed in the Namib Desert near Gobabeb (Namibia) as well as 10 AWSs in the Namibe Province, south-west Angola in 2014. In early 2015, further 37 AWSs spread over the region and supporting specific research projects are put into operation by SASSCAL respectively.

All new and rehabilitated stations are equipped with WMO-certified sensors measuring rainfall, temperature, solar radiation, wind speed and direction, relative humidity and barometric pressure, all at a temporal resolution of either 15,30 or $60 \mathrm{~min}$ intervals. Depending on research requirements, stations are upgraded with additional equipment measuring sunshine duration, leaf moisture, soil moisture and fog in selected locations. In order to facilitate near-real time data availability, data transmission is primarily based on mobile communication technology (GPRS/GSM). However, 8 stations at remote sites use satellite-based data transmission (supported by EUMETSAT, based on METEOSAT), and additional 7 satellite-based stations are planned for installation in 2015. The observations are transmitted to the SASSCAL WeatherNet server, and additionally to various SASSCAL partner institutions. In Namibia, data are transferred to the National Botanical Research Institute as well as the Gobabeb Research and Training Centre, while in Angola, Botswana and Zambia, the data are also collected by the national meteorological services. Altogether, the current SASSCAL station network comprises of 113 stations in the region and will, in cooperation with other activities, increase to 148 in 2015 (see Fig. 3). 


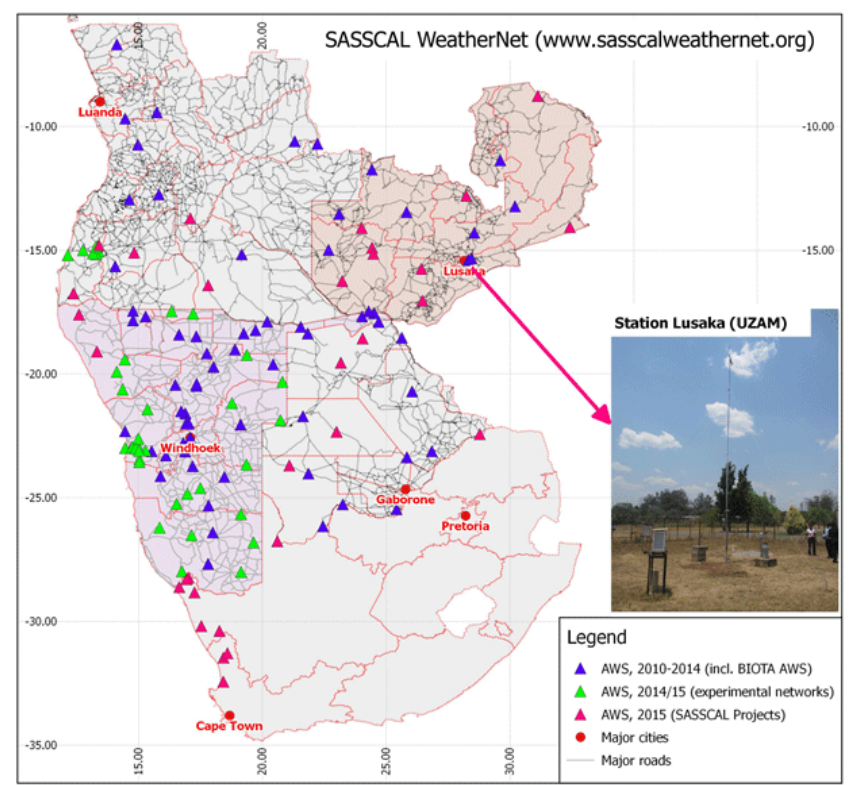

Figure 3. Location of observing stations supported by SASSCAL (including stations installed by BIOTA AFRICA). Data from these stations are available at www.sasscalweathernet.org. Note: Additional five AWS will be installed within a radius of $20 \mathrm{~km}$ South East of Gaborone City, i.e. upstream of Gaborone Dam.

According to the SASSCAL mandate the data are made freely available to the public at the SASSCAL WeatherNet website. Currently, data of 105 stations are available online, with time series partly starting in 2010 . Technically, station data are provided by six different transmission systems which vary by country and provider. Thus, data flow procedures and data protocols were unified for harmonization purposes. Incoming data are (automatically) checked in terms of homogeneity and consistency and corrected before getting stored in a relational data base system. A user-friendly web-interface (Fig. 4) based on MySQL and PHP technology was developed allowing users to get an overview on the actual condition at each station, to visualize and download data as well as to explore various statistics. All measured values are available for download in 15 or 60 min resolution. In addition, daily and monthly averages, diagrams for individual parameters, near real-time rainfall information and station information sheets are provided on the website. Users can also subscribe for an e-mail-based daily weather report.

With these efforts, SASSCAL WeatherNet provides not only data and information for its research community as for example projects in the water sector (Helmschrot and Jürgens, 2015), but also for collaborating agencies and activities (e.g. FEWS NET, the Famine Early Warning Systems Network), many local and regional stakeholders (e.g. farmers, lodge owners) and the public (e.g. radio stations).

\section{Climate data management}

For sustainable archiving and efficient utilization of the climate data within the national meteorological and hydrological services (NMHSs), a specialized data base system is required, typically called "Climate Data Management System (CDMS)". During the last decades different systems have been in use in developing countries (see Stuber et al., 2011) and different approaches for their development can be identified (e.g. developed by an NMHS or commercial products).

The improvement of concepts for data management and the completion of the data bases at the NMHSs is an additional aim of SASSCAL. This topic was discussed among the NMHSs of Angola (Instituto Nacional de Meteorologia e Geofisica, INAMET), Botswana (Department of Meteorological Services, DMS), Zambia (Zambia Meteorological Department, ZMD) and Germany (DWD) during a SASSCAL Climate Workshop (http://www.sasscal.org) held in Namibia in April 2014. The group agreed that harmonization of concepts in the region is desirable. A discussion of available options led to the conclusion that the approach of CLIMSOFT ("CLIMatic SOFTware") was a promising option to fulfill the specific requirements for these countries, considering the enhancements that are being planned (see below).

CLIMSOFT was originally developed by an African team of 3 developers located in Zimbabwe, Kenya and Guinea (Stuber et al., 2011). The aim for the development of CLIMSOFT was to provide a free and easy-to-use CDMS for developing countries. It has an intuitive Graphical User Interface, a key-entry module, quality control procedures and allows data import from various sources, including data from automatic weather stations. It allows data export into several formats and generation of products and summaries.

The software is currently based largely on the data base management system (DBMS) Microsoft ${ }^{\circledR}$ Access and Microsoft ${ }^{\circledR}$ Visual Basic 6, but enhancements to the software, and a switch to open-source solutions are currently in preparation. However, the open-source data base system MySQL has already been widely used as a back-end to the MS ${ }^{\circledR}$ Access DBMS to meet the needs of NMHS with larger volumes of climate data and also at regional centers like the African Centre of Meteorological Applications for Development (ACMAD).

\section{Capacity development and training activities}

A major component of all SASSCAL activities is the development of capacities and associated training in collaborating institutions. As a capacity development effort during the buildup of the SASSCAL WeatherNet, technical staff at all involved institutions was trained on technical requirements regarding the installation and maintenance of the different types of automatic weather stations during the installation campaigns, but also on the technical aspects of data transmission, management and publication. 


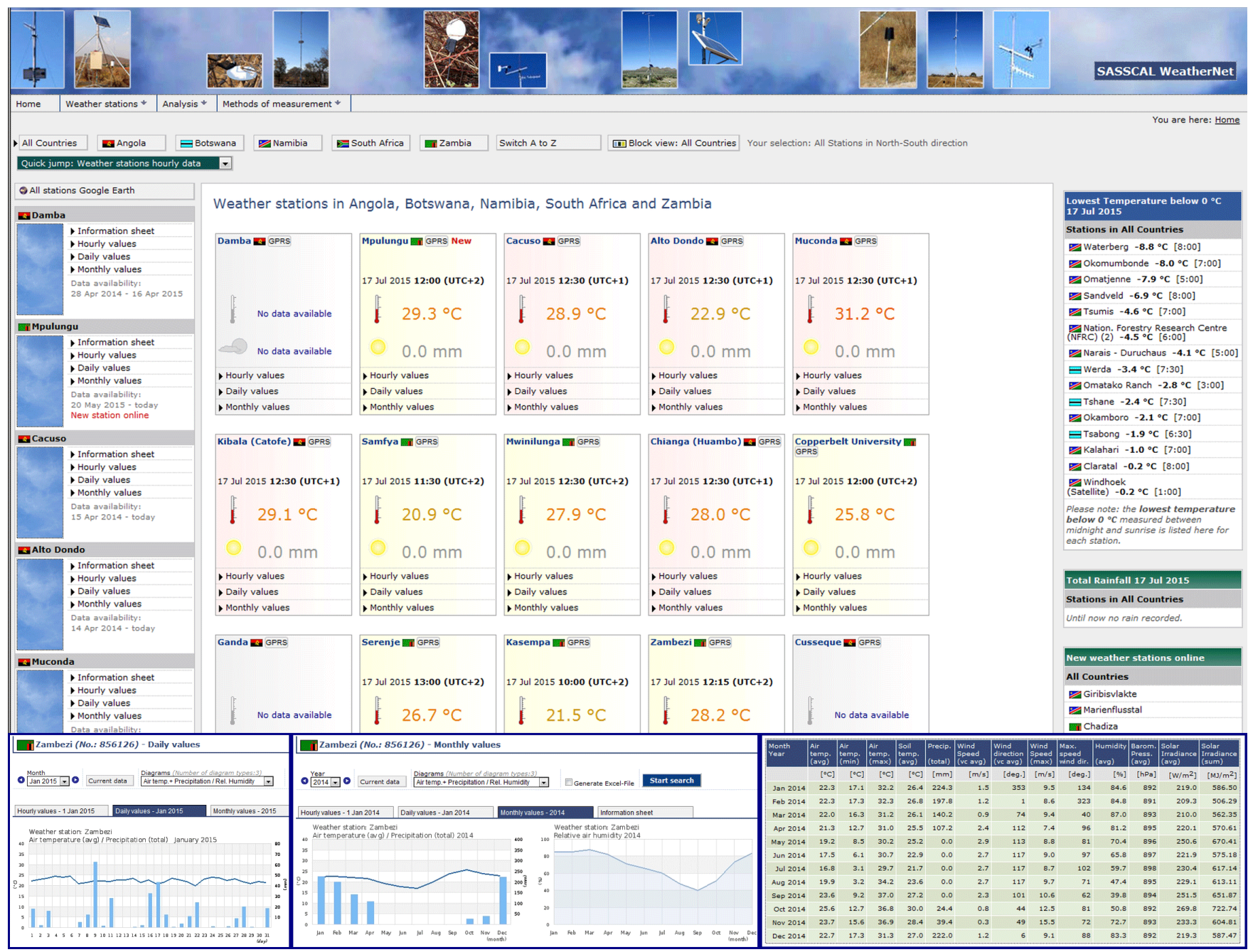

Figure 4. User interface and tools of the SASSCAL WeatherNet (www.sasscalweathernet.org). The upper figure shows the welcome page providing a general overview on actual climate conditions at each station and the actual rainfall status. The lower figures illustrate summaries of station-based daily rainfall and temperature in January 2015 (lower left), monthly summaries for 2014 (lower central) and statistics for 2014 (lower right) at an example for the Zambezi station.

One important conclusion of the SASSCAL Climate Workshop was that training activities related to climate data management are needed for the staff of the meteorological services. DWD now works together with the national meteorological services of Angola, Botswana and Zambia to train the local staff in charge of data management. One major aim of the cooperation is to ensure the proper operation and more holistic operation of CLIMSOFT in the long-term.

When conceiving the priorities of the training, the specific needs of each service are taken into account and therefore, the capacity building activities differ from one country to another. However, two common priorities can be pointed out: to improve the skills of the local staff in dealing with climate data (e.g. the importance of metadata and homogenization); and to raise awareness for the importance of documenting the processes and routines related to data management.

\section{Extension of archives and data rescue}

During the SASSCAL workshop it was also stated by the NMHSs that there is a need for data rescue activities in order to complete the data bases and to assure that historic data do not get lost. Data Rescue is the ongoing process of (1) preserving all data at risk of being lost due to deterioration of the medium and (2) digitizing current and past data into computer compatible form for easy access (Tan et al., 2004). Gaps in existing time series of the national meteorological services can eventually be filled with data from existing national or international archives. One example are the time series of precipitation that are available in the archive of the Global Precipitation Climatology Center (GPCC; http://gpcc.dwd.de), hosted at DWD. It collects precipitation observations from various sources and provides 


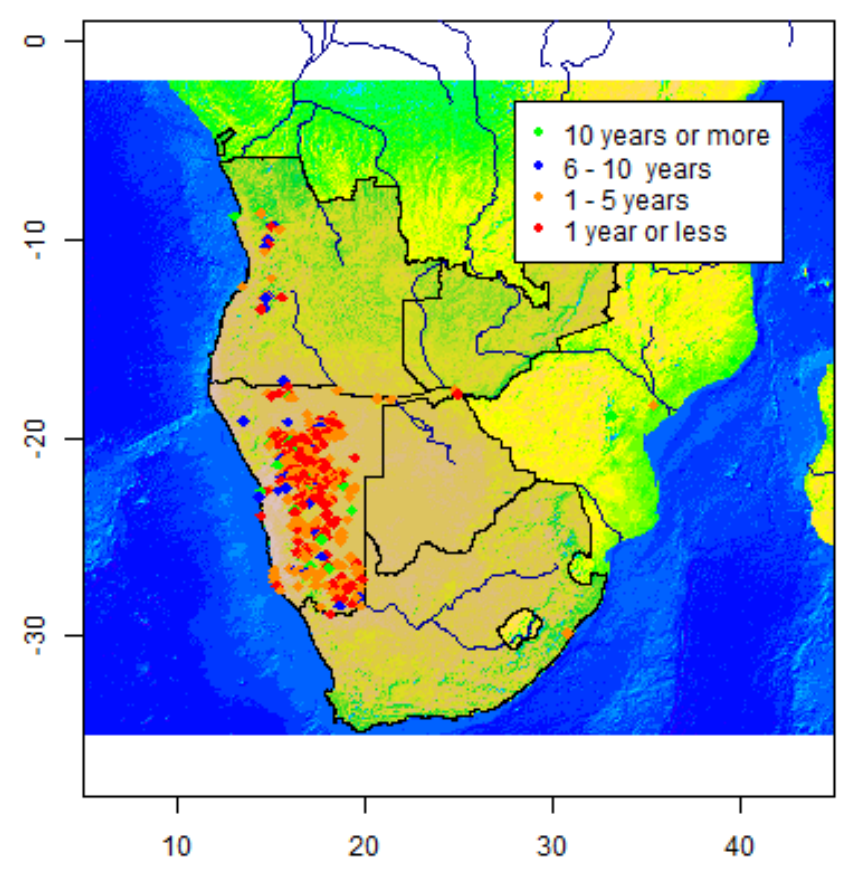

Figure 5. Location and length of the longest observation interval of overseas stations of the German Naval Observatory ("Deutsche Seewarte"; 1830-1943) that are available in the archives of Deutscher Wetterdienst as original paper documents. DWD works on the digitization of these data (Kaspar et al., 2015).

gridded global precipitation data covering the period 1901 to today (Becker et al., 2013). It receives precipitation data from various NMHSs, partly on a regular basis, but according to its mandate, the original data are not distributed to third parties. However, the assessment of national data bases of the SASSCAL countries revealed that the original data were not available anymore in some of the national archives. First steps have now been undertaken to integrate these time series into the national archives again. DWD currently also works on the digitization of observations that are available in its archive from colonial times (Fig. 5; Kaspar et al., 2015). Time series from several stations in the regions are also available on paper at the Gobabeb Research and Training Center (Namibia).

\section{Conclusions}

SASSCAL, in close cooperation with the national weather authorities, supports the rehabilitation of existing station networks and the installation of new fully automated weather stations in Angola, Botswana, Namibia, South Africa and Zambia and thereby contributes to national and international climate initiatives. This is achieved by provision of consistent, reliable and up-to-date information, as well as providing capacity development and training activities at the meteorological services. With the integration of these stations into the SASSCAL WeatherNet, the measured time series are made available to a large number of stakeholders in near-real time and open access. With future installations, the observation network will be expanded. In addition, other activities like a United Nations Development Program project on early warning systems at the Zambian Meteorological Department or a new installation campaign in Botswana built on the developed skills and the technological infrastructure and align their efforts regarding the positioning of new weather stations and technological integration.

Technical support and capacity building activities are performed in order to improve the data management at the NMHSs. The NMHSs agreed on a harmonized approach for their internal climate data management systems based on a freely available Climate Data Management Software. Data sources have been identified that will allow the extension of data bases with additional historic data. In total, the ongoing activities will contribute to the strengthening of regional capacity to provide information on regional climate change and thereby providing important information for the sciencebased decision making for adaptation to climate change.

Acknowledgements. The authors would like to thank the German Ministry for Education and Research (BMBF) and its cooperating African ministries for funding SASSCAL. We are also grateful to the technical staff assisting the operation of the system at all involved institutions. We thank EUMETSAT for supporting the satellite-based data transmission. Two anonymous reviewer gave helpful comments on the manuscript.

Edited by: G. van der Schrier

Reviewed by: two anonymous referees

\section{References}

Becker, A., Finger, P., Meyer-Christoffer, A., Rudolf, B., Schamm, K., Schneider, U., and Ziese, M.: A description of the global land-surface precipitation data products of the Global Precipitation Climatology Centre with sample applications including centennial (trend) analysis from 1901-present, Earth Syst. Sci. Data, 5, 71-99, doi:10.5194/essd-5-71-2013, 2013.

Helmschrot, J. and Jürgens, N.: Integrated SASSCAL research to assess and secure current and future water resources in Southern Africa. Hydrological Sciences and Water Security: Past, Present and Future, Proc. IAHS, 366, 168-169, doi:10.5194/piahs-366168-2015, 2015.

IPCC: Climate Change 2014: Impacts, Adaptation, and Vulnerability. Contribution of Working Group II to the Fifth Assessment Report of the Intergovernmental Panel on Climate Change, Cambridge University Press, Cambridge, UK and New York, NY, USA, 2014.

Kaspar, F., Tinz, B., Mächel, H., and Gates, L.: Data rescue of national and international meteorological observations at Deutscher Wetterdienst, Adv. Sci. Res., 12, 57-61, doi:10.5194/asr-12-572015, 2015.

Schneider, U., Becker, A., Finger, P. Meyer-Christoffer, A., Rudolf, B., and Ziese, M.: GPCC Full Data Reanaly- 
sis Version 6.0 at $0.5^{\circ}$ : Monthly Land-Surface Precipitation from Rain-Gauges built on GTS-based and Historic Data, Deutscher Wetterdienst, Global Precipitation Climatology Center, doi:10.5676/DWD_GPCC/FD_M_V6_050, 2011.

Stuber, D., Mhanda, A., and Lefebvre, C.: Climate Data Management Systems: status of implementation in developing countries, Clim. Res., 47, 13-20, doi:10.3354/cr00961, 2011.

Tan, L. S., Burto, S., Crouthamel, R., van Engelen, A., Hutchinson, R., Nicodemus, L., Peterson, T. C., and Rahimzadeh, F.: Guidelines on Climate Data Rescue, World Meteorological Organization, WMO-TD No. 1210, 2004.
World Meteorological Organization (WMO): Annex to the Implementation Plan of the Global Framework for Climate Services Capacity Development, Geneva, Switzerland, 2014a.

World Meteorological Organization (WMO): Annex to the Implementation Plan of the Global Framework for Climate Services - Observing and Monitoring Component, Geneva, Switzerland, 2014b. 